\title{
Doing the job in surgery 2017: you and your theories
}

\author{
F. M. Riegler
}

Published online: 13 January 2017

(C) Springer-Verlag Wien 2017

\section{Dear reader,}

Welcome back from influential seasonal holidays, greetings and highly outbalanced relaxations, with and without the presence of family and geographic translocation towards areas with a more favorable climate for whatever you considered to define "perfect" and more than that. Outcome counts. Diagnosis provokes reaction. Lack of time fosters statistics only based therapies. No time for reflection. Whom the bell rang sheds a light on the state of affairs of our I and I civilization. Nowadays it seems justified to follow a tolerant path of reasoning. Here we go.

This issue of European Surgery incorporates a highly motivating spectrum of colorful observational studies and new kids on the block perceptions. The polyphony ranges from hepato-very-biliary motives, pancreatic duct the hut surgery, distinct chant of gall bladder polyps, the impact of circulating tumor cells for outcome after diagnosis of pancreatic cancer; next we report on the nocturnal selections of types of anastomosis during kidney transplantation; finally we present the impact of a novel glue for mesh fixation during innovative laparoscopic inguinal hernia repair. In addition, a case report of the successful management of a rare condition, i. e., pregnancy of a woman with Marfan syndrome, a specific connective tissue disorder, is presented. Finally, teaching and education beautifully pushes a theme of outstanding and major importance in surgery: perioperative fluid management. Here we go and learn, while the planet has to turn.

Feel free to skip to the last few paragraphs, i. e., the conclusion, if you do not have find time to consider

\section{F. M. Riegler ( $₫)$}

Reflux Medical, Mariannengasse 10/9, 1090 Wien, Austria martin.riegler@refluxmedical.com the value of essence-based reasoning in medicine. You may return to those lines later in an hopefully more favorable mood and setting, when compared to the sterile, cool climate of the operation theatre, hospital wards, and office facilities. Due to the current global developments the author feels that the considerations raised in this article are of major relevance, actuality and importance for surgeons, physicians, and human beings all over the world. Repeated regularity counts.

While you continue to read those lines, there happens the background against which you are. How (paper form vs. digital version) and where you may read those lines-i.e. in your office, wards, cafe, restaurant, fitness center, car in a traffic jam, railway station, rest room, train, airport, airplane, beach, river side, garden, park, pub(lic), underground station, tubing yourself through the bowels of your city or in one of the multiple well-designed cuboids of your medical institution-it all happens AGAINST the background: with an enormous speed over time our home planet takes us through space, around the sun, while it turns around its own axis, producing days, nights, precession, seasons, great and small years, rain, floods, rivers, seas, mountains, and deserts. In addition, we curve within the arms of our galaxy, which in turn speeds around other galaxies and subsequent waves of perceptions, as known by astronomy. As a matter of fact, there is no proof that the universe really exists as we consider it to be, and thus it has to remain a theory. But as long as theories work and contribute to explain our existence, behavior, life quality, and success, we should take them as granted. This all has been orchestrated out in the form of fantastic myths and academies all over the globe. Pulsatile wisdom counts.

The truth is what is going around in your brain? The ancient is the oldest and repeatedly translates the very common theme of our world and civilization into the 


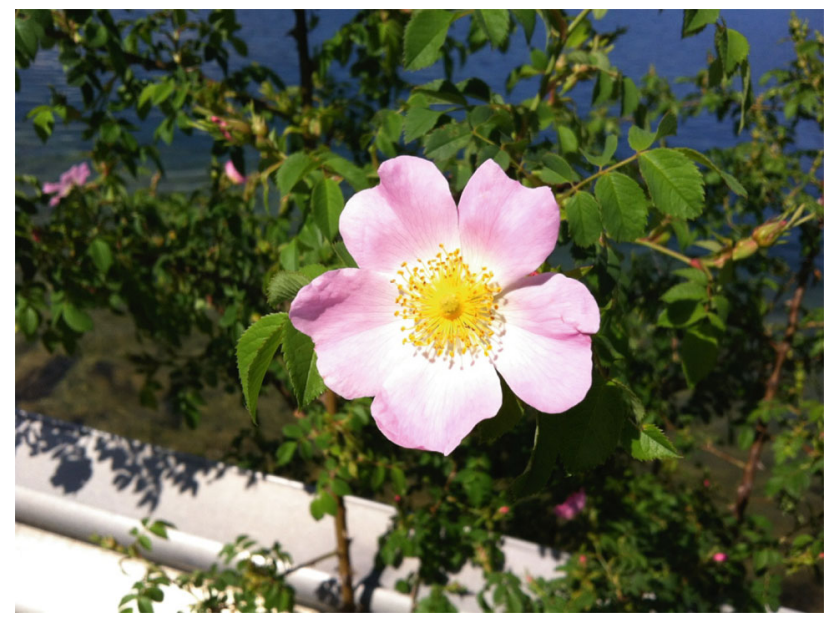

Fig. 1 Sun activates a flower to open into full bloom and thus serves to pleasure our attention and perception. The image mirrors the idea of the author that all perceptions and phenomena are a consequence of the unfolding of manifestations of astronomy - driven circuits of spheres. Image obtained at Traun Lake, Upper Austria

perceivable forms of art: the essence behind all matter, beyond all things and perceptions is (existing duration without time and space) and usually hides itself from being assessed and unfolded by our reasoning (Fig. 1). As a consequence it seems that the reasoning itself equals the essence, and the being is the individualized sound manifestation of the universal cosmic consciousness, thus we are consciousness. Only a view of us may be allowed to face the most striking moments of existence, where the hidden essence unfolds itself and comes into our perception for short moments of bright thunder and emotion. Such moments translate into statements including: "Thinking and being are the same" (Parmenides), "The world is you" (Upanishad), "One cannot reason the being" (Vedas), "There is no star without a companion" (Pyramid Texts) and "Life is a stream of mood and emotions" (Walt Whitman). These are those short lightning moments, where we think to be enabled to face the essence, where we think we are allowed to catch the truth. Subsequently follows an episode of mood, which is remembered as a state of specific estimate of knowledge. What remains is a taste of pulsatile taste of understanding. Since we are taken away from the essence by our every day job, our everyday surgeries, endoscopies, strokes on greed, hate, warfare, and anger, taking of the patient histories, we are not allowed to open ourselves for these streams of mood and perception. What remains to be questioned if our inability to adequately and frequently sense and unfold the hidden may in fact influence our daily routine from diagnosis to therapy and economic considerations in medicine? Could short moments of focus on the above theme positively alter the tune of our life and improve our performance? Should we open ourselves to allow such moments of enlightenment? Tuning counts.

At present it seems that science replaces religion and insecurities that are not adequately explained by science are taken up and re-satisfied by (some sort of) religion. Patients need physicians, who take more time to listen to their stories, myths and poetries. Many individuals perceive a lack of attention, respect, love and affection. Due to the rapid beat of the modern life pace maker-i. e. computer technology-desires, perception, and decision making have changed in favor of "reaction". Prior to that episode of human existence there has been the period of slow mission finding and reasoning. Second, humans cry out for knowledge and want to understand the causes of a given phenomenon. Therefore, theories aim to model and replace belief. As long as theories work, it does not matter to waste time and space on the matter to search for a truth.

For example, we create a machine which enables us to detect a "new" dalton brother receptor protein, name it XY receptor. We find that the XY receptor is overexpressed at all levels of keepers of information (mRNA, DNA, cell membrane, etc.) within tumor cells, when compared to normal tissues $(p<0.005)$. Next we find that inhibition of this XY receptor by the administration of an anti-XY receptor molecule attenuates the growth of tumor cells in vitro $(p<0.0001)$. Next, data obtained in animals, extend the in vitro observation to the in vivo condition $(p<0.002)$. At this point starts the fascinating process of translation: the in vitro and the in vivo animal data are now translated into the human Gesamtkunstwerk. Clinical phase studies are implemented and demonstrate striking and highly promising data. We observe that the inhibition of a given specific receptor XY blocks tumor cell growth in humans and contributes to increase the cancer specific survival $(p<0.001)$. Here it is fine to assume that inhibition of the $\mathrm{XY}$ receptor does the job, irrespective of the possibility that the effect could also have been achieved by an alternative mechanism, i. e., the "signs" of which have not come to our perception so far. Why? Because we do not possess the system to assess those "signs" of a possible alternate XY receptor independent pathway. We do not operate the machines to decode and translate the signs, to make them perceivable for us. Theory counts phenomena.

Going in line with the above suggestion-i.e. being out of the range of our perception due to the fact that we lack the respective sensory mechanism for accurate assessment of "alternative" pathways of action-we repeatedly observe that survival is only improved in a small portion of all patients with this respective tumor, i. e., only $5-20 \%$ of patients benefit from the therapy (anti-XY receptor therapy); the others perceive the so-called side effects and painfully, desperately vanish early (six feet at last for sure, but earlier). However, the difference between the long- 


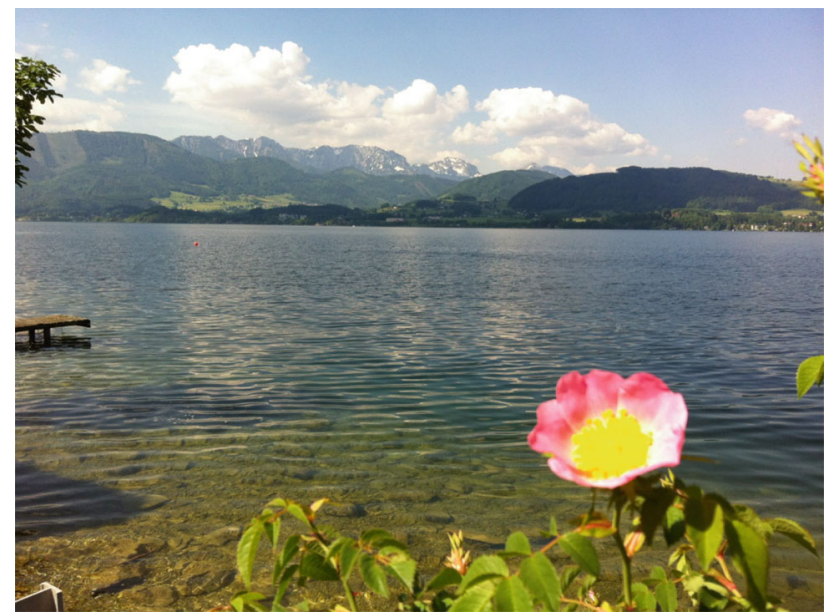

Fig. 2 Perspective alters the tuning of perceptions. As thus the flower becomes the beauty against the background of a lake, mountains, sky, universe, etc. The image mirrors the idea that all perception occurs against a background, physical and intraphysical, as outlined in the text. Image obtained at Traun Lake, Upper Austria

and short-term survivors shows a statistically significant difference $(p<0.001)$. Thus, the therapy is considered effective and becomes published in the best journals of our wonderful, beautiful planet earth. Mother takes it all. As a consequence, based on the new XY receptor theory at work, the economy commences to chant the song of success. Taken together, we become critical in using essence-based reasoning and summarize: our model mirrors a setting of information which has been obtained by a chain of machine-generated data and subsequent interpretation of the data using the colorful firework of statistics to outline "our" theory; assessment of the receptor protein qualities; in vitro bioengineering using a small segment of a tumor cell population, i. e. cell clone; in vivo data (phenomena) obtained genetically manipulated knock in our out animals. Missing the essence counts.

For those individuals who benefit from the therapy we conclude the following: since the model works-XY receptor inhibition stops cancer growths-it can be accepted for truth, matter of fact, and fully explains the success of the treatment. No further investigation seems to be necessary. In contrast to that, treatment failure stresses one to rethink knowledge and continue to proceed into depth $(p>0.05)$. For those individuals, who did not benefit from the therapy we state the following reasons for the failure of the therapy including alternate, therapy resistant tumor cell clones, tumor stage migration (understaging of the tumor due to lack of adequate diagnostic sensitivity) and the assumption that another, alternate receptor mechanism may be at work, too, which we have not found so far, due to the lack of adequate machines for detection of these receptors (=the future of oncology). It remains to be questioned whether being itself hides us from knowing the truth?

It seems that we have lost the capability to read and speak the universal language of the stars, the melody of astronomy, and since these Babylonian days we are stuck in separation and machine-based generation of data, technologies and translations of phenomena and information. We have closed the open eye for the essence and commenced to miss it, lose it, and forget it. Here comes the ancient Greek story of river lethe. According to Platon, those who drink lethe forget about their earlier and previous existence and thus become ready for the next form of manifestation, i. e., reincarnation. As such we are hidden from the essence, we have lost our sensitivity for the cycles of the heavenly spheres of fire (Heraclitus). As thus obtaining a perception equals reasoning equals existence equals being equals the I, equals consciousness, equals the truth (Parmenides). Amplification counts.

Architecture, music, painting, art aim to amplify essential signs, states of mood and emotions and thus transform it into a manifestation, which in turn, is perceivable to us in the form of sound, image, smell, tune, vibrations, pulses, and repetitive circulations of the basis of our colorful existence: the tune of mood, the continuous flow of being and emotion (Fig. 1). Name it as you will, it is out there. Term it physical if you can perceive and measure it (MRI, CT scan, sonography, manometry, endoscopy, laparoscopy, body monitoring, ERCP, INRI etc.); if you lack a measure for feel, name it spirit, soul, thought. Do not name it meta-physics because it does not add to the limits of our perception; it is meant to name the invisible form of energy within the perceivable physical world, so it therefore deserves the name intra-physical. And the intra-physical helps to approach and sense the cause. Thus, we should consider any form of energy when treating a perception, when managing a medical condition, when acting as surgeons of phenomena, when closing wholes, wounds, and wings, when operating stents, tubes and balloons, when we are decreasing tumor loads, when resecting fertile land, lions, aquarius, taurus, and scorpions. What sounds through all phenomena and matters as the causative shine is the intra-physical, not measurable stream of feel, mood and idea. This sound seems to be an outstanding gift: our consciousness. And we may share our consciousness with other beings, here and elsewhere. This may at least in part be valuable to explain the reported success of so-called ancient knowledge-based medicine (China, India, the Americas). Taken together, all perception happens, develops, and vanishes against the background of physics and intra-physics (Fig. 2) and is. Tree talks to man, flower, river and birds (North American Cherokees mythology). Metaphysical reasoning aims to justify our technology-driven power geames within the physical world. Energy counts. 
The more movie we "know" the bigger gets our emotional insecurity and instability. Life quality impairment strategies are highly effective implemented into our modern life (technological revolution, computer-based global village, applied for applications, side effects of the products of the food and beverages industry, etc.). And there we end up at imaging the paper that will never be written, submitted, and accepted. We will end up at the tables and figures that will never be plotted against the above mentioned back ground: there would have to be a blank unwritten piece of quiet peace containing all possibilities, rumors, and tendencies of the all. Back to the ground we go and there we should thank the beauty of our globe for giving us the background for our lives. It remains to be questioned whether there is , a real aim for human beings to stay on this planet? What for are we here? Why do we live on this planet?

Physically taken you may name it: will for power, if it were out of the reach of physics, name it sound for spirit and soul. Going in line with history, the past and the present times are telling us, that: we are experts of the will for increasing the power (oncology, high volume surgery). In contrast, if you open your eyes and ears to watch out and listen, you may be excited about an astonishing shine: out there within the outer limits of the universe at the level of the delicate skin of silence our noises are reflected as pure being and emotion. No light, no sound, no perception, the one we cannot think about. Spirit and thought fuse, being and reasoning name the same. Beyond that, space keeps the secret of time and essence-directed science may provoke a new start. Background counts.

Assume that at least once a day you may allow such thoughts, as reasoned above. Test if it may contribute to increase your life quality and wellbeing. Maybe such an approach may contribute to deepen humility and thankfulness. In addition, considering our background may foster enlightenment without greed, envy, and hate. Thus, it may help you to be better at work and successful in your achievements. Taken together it may lead you to live happy. Back to the ground, counts.

Taken together the above considerations sum up with the following conclusion: The truth is, what is going around in your brain. You may call it the individual and/or cosmic consciousness, being, matter of fact, the essence, the intraphysical, the I and I, the tune of mood or the continuous stream of emotion. Further linguistic unfolding does not seem possible. Irrespective if and how and is as much you think about the "essence", it is out of the reach of our reasoning to understand what sounds behind, through, and within all phenomena. But none the less it is out there, name it as you will, it exists, sounds through and influences, mediates and sustains your medical work, diagnosis, therapy, follow up examinations, and your basic science investigations. Even during large surgical procedures (open and/or supra - minimally invasive) using advanced surgical skills and expertise, the unfolded hides behind your actions. Therefore, the above suggestions and considerations seem to be, at least in part, justified and therefore should be brought to your attention. May these lines stimulate and provoke your own reasoning towards the essence and manifest in the form of short moments of thankfulness, humility, and passion. The planet earth takes it all, as long as we do not over do. It remains to be questioned whether we have already reached the limits?

Stay tuned and prosper, may you find time to get back ground against (y)our background at least once a day in 2017.

Acknowledgements The author thanks the beautiful planet earth for having the huge passion for taking us around through space and time and providing us the most beautiful manifestations of our consciousness. May the earth continue to do so, irrespective of the mad alterations of many of us in the medical and non-medical arena.

Conflict of interest F.M. Riegler declares that he has no competing interests. 